\title{
ART-naive HIV patients at Feleg-Hiwot Referral Hospital Northwest, Ethiopia
}

\author{
Bayeh Abera $^{1}$, Fisseha walle ${ }^{2}$, Tsehaye Tewabe ${ }^{3}$, Atnaf Alem², Mohammed Yessin ${ }^{4}$
}

\begin{abstract}
Objectives: To determine socio-demographic and immunological status of anti-retroviral treatment (ART)-naïve HIVpositive patients.

Methods: This was a longitudinal survey of HIV-positive patients treated with ART at Felege-Hiwot Hospital. CD4 cell counts were enumerated at baseline and after 6 months of treatment using FACS count (Becton Dickinson). Socioeconomic data were collected using pre tested questionnaires.

Results: Three hundred sixty eight (62\% female), with median age 30 years were enrolled. Of these, 207 (56.5\%) were uneducated and $233(66.8 \%)$ had monthly income $\leq 250$ birr. Three hundred fifteen (85.6\%) started ART within 6 months of HIV diagnosis. The mean (95\% CI) CD4 cell count at baseline was 153 (139-167); 156 (137-175) for females and 122 cells $/ \mu 1(105-139)$ for males $(\mathrm{p}<0.01)$. At baseline, $280(76.3 \%)$ and $134(36.4 \%)$ patients had CD4 cell count $<200$ and $\leq 100$ cells $/ \mu 1$, respectively. Six months follow-up CD4 counts were enumerated for $225(61 \%)$ patients and their mean CD4 cells increased from $143-261$ cells $/ \mu 1(\mathrm{p}<0.05)$ with a mean cell gain of 117 cells $/ \mu 1$. Of the 166 follow-up patients withCD4 count $<200$ cells/ $\mu 1$ at baseline, $130(78 \%)$ attained a higher CD4 cells count after treatment compared to $50(85.6 \%)$ of the 59 with $\mathrm{CD} 4$ cell $>200$ cells $/ \mu 1(\mathrm{p}=0.21)$.

Conclusion: In this setting, HIV patients started ART with lower mean CD4 cell counts of 153 cells $/ \mu 1$ and most patients with low baseline CD4 cells $(<200$ cells/ $\mu$ l) counts didn't achieve an increase in the number of CD4 cells after treatment. The majority of ART-naïve HIV patients were from low levels of education and with minimum monthly income. Appropriate interventions should be implemented to promote and enable HIV positive individuals to enter into ART programs as early as possible [Ethiop. J. Health Dev 2010;24(1):3-8].
\end{abstract}

\section{Introduction}

An estimated 31 million adults worldwide were living with HIV and of these 2.3 million were newly infected with the virus and 1.7 million died of HIV/AIDS in 2008 (1). Sixty seven percent of HIV infection worldwide, $68 \%$ new cases among adults with $72 \%$ of AIDS related deaths were estimated in sub-Saharan Africa in 2008. According to the World Health Organization (WHO) estimation, nearly 3 million people living in low and middle-income countries (LMIC) were receiving Antiretroviral Therapy (ART) at the end of 2007 (2). According to the UNIAIDS/WHO update data the number of AIDS-related deaths has declined by over $10 \%$ over the past five years due to antiretroviral treatment (1).

In Ethiopia, approximately one million people are living with HIV which has become the leading cause of mortality among 15-49 years of age, that accounts for about $43 \%$ of all population in 2008 (3). ART was started in the country in 2003 and free ART was launched in 2005. In 2009, 93 public hospitals, 47 private hospitals, 12 military hospitals and 292 health centers and 3 nongovernmental organization clinics were providing HIV care and treatment services in all regions of the country (4). The prevalence of HIV infection is the highest in Amhara regional state where this study was based compared to other parts of Ethiopia. In the region, more than 97,588 cases needed ART and only 38,067 (39\%) were able to be treated in 17 hospitals and 62 selected health centers (5).

HIV infection causes progressive depletion of CD4 cells, which leads to immunodeficiency syndrome with a wide range of opportunistic infections and malignancies that eventually leads to death. Several studies indicated that proper use of antiretroviral treatment substantially reduces morbidity, mortality and prolongs life expectancy of HIV/AIDS patients $(1,6-8)$. However, there are numerous factors that could limit its effectiveness especially in resource limited settings. Studies indicated that the response of ART varies among population due to differences in viral subtype, host factors, co-infections, such as tuberculosis (TB), other bacterial diseases or socioeconomic status and environment (9-11).

Various studies in sub-Saharan Africa and in low income settings reported that many HIV infected patients are accessing antiretroviral treatment program after developing advanced immunodeficiency (12). This study was conducted to explore the socio-demographic characteristics and immunological status of ART-naive

\footnotetext{
${ }^{\mathrm{T}}$ Microbiology and Immunology department, College of Medicine and Health Science, Bahir Dar University, Ethiopia

${ }^{2}$ Regional Health Research Laboratory Center, Bahir Dar, Ethiopia

${ }^{3}$ Bahir Dar Health Sciences College, Bahir Dar, Ethiopia

${ }^{4}$ Liverpool School of Tropical Medicine, Liverpool, UK,
} 
HIV- infected patients attending Felege Hiwot Referral Hospital, Northwest Ethiopia.

\section{Methods \\ Study design and area}

A longitudinal study was done from September 2008 to August 2009 at Felege Hiwot Referral Hospital, that is one of the government sponsored ART centers at Bahir Dar town; the capital of Amhara Regional State, North West Ethiopia.

\section{Study population}

All volunteer ART-naïve HIV-infected individuals age above 15 years who were initiating ART were enrolled consecutively and followed for six months. During enrolment for ART, socio-demographic data including gender, age, income and educational status were recorded by ART trained physicians using a structured and pre tested questionnaire. Participants were asked when they were first tested for HIV and the reason why they were tested.

\section{CD4 cell counts}

At initiation of ART and after 6 months of treatment, 4 $\mathrm{ml}$ venous blood was collected from each participant using K3 EDTA vacutainer tube. CD4 T cells and CD8 T cell counts were enumerated using FACS (Fluorescent Antibody Cell Sorter, Becton Dickinson).

\section{Statistical analysis}

Data were entered and analyzed using SPSS window version 16. Categorical variables were tested by chisquare tests and $\mathrm{p}$ - values $<0.05$ were considered to be statistically significant.

\section{Ethical considerations}

Ethical approval was secured from Research Ethics Committee of the College of Medicine and Health Science of Bahir Dar University as well as from Bahir Dar Regional Health Research Laboratory. Informed consent was obtained from each study participant.

\section{Results}

\section{Socio-demographic characteristics}

Among a total 368 patients recruited, 227 (61.6\%) were females. The median age of the participants was 30 years (range 15-65years) and 73.6\% were age between 20 and 40 years. The majority of the participants $207(56.2 \%)$ were illiterate and had low economic status 233 (66.8\%) as defined by their monthly income (Table 1). Among 263(75.4\%) the main reasons for being tested for HIV was related to experiencing repeated and/or persistent risky sexual behavior. The time interval between the first HIV testing (knowing their HIV status) and date of staring ART was very short. Since the majority [315 $(85.6 \%)]$ of HIV patients started ART within 6 months and $14(3.8 \%)$ between 6 months to 1 year from the date of diagnosis (Table 1).

\section{Common Opportunistic Infections and co-morbidities}

We have attempted to determine the common opportunistic infections, which are cause of morbidity and mortality among HIV-infected patients at baseline. In this study, at baseline, $327(88.9 \%)$ HIV patients presented with common opportunistic infections. Of these, 143 (38.6\%) had chronic diarrhea, 127 (34.5\%) with TB, $113(30.7 \%)$ with herpes zoster, 52 (14\%) with Oro-pharyngeal candidiasis, $13(3.5 \%)$ with pneumonia and $46(12.5 \%)$ with other sexually transmitted infections (STI) as shown in (Table 2).

Table 1: Socio-demographic characteristics of ART naïve HIV patients at Feleg Hiwot Hospital, Ethiopia, 2008

\begin{tabular}{|c|c|}
\hline Participants Characteristics & $\begin{array}{l}\text { Frequency } \\
N(\%)\end{array}$ \\
\hline \multicolumn{2}{|l|}{$\begin{array}{l}\text { Time interval from HIV diagnosis to } \\
\text { commencing ART }(N=368)\end{array}$} \\
\hline Within 6 months & $315(85.6)$ \\
\hline 6 months to 1 year & $14(3.8)$ \\
\hline 1 to 2 years & $22(6)$ \\
\hline $2-3$ years & $13(3.5)$ \\
\hline$>3$ years & $4(1.4)$ \\
\hline \multicolumn{2}{|l|}{ Education status $(\mathrm{N}=368)$} \\
\hline No formal education & $207(56.2)$ \\
\hline Primary (grade 1-6) & $36(9.7)$ \\
\hline Secondary complete (grade $7-12$ ) & $31(8.4)$ \\
\hline High school complete (grade 12) & $65(17.6)$ \\
\hline Above high school (grade $12+$ ) & $29(7.8)$ \\
\hline \multicolumn{2}{|l|}{$\begin{array}{l}\text { Reason for getting HIV testing } \\
(\mathrm{N}=349)^{*}\end{array}$} \\
\hline Due to repeated illness & $263(75.4)$ \\
\hline Risk sexual behaviors & $41(11.7)$ \\
\hline After death of spouse & $11(3.2)$ \\
\hline Premarital testing & $7(2)$ \\
\hline Provider initiative counseling and testing & $10(2.86)$ \\
\hline Others & $17(4.8)$ \\
\hline \multicolumn{2}{|l|}{$\begin{array}{l}\text { Income per month ( Ethiopian birr) } \\
(\mathrm{N}=349)^{*}\end{array}$} \\
\hline$\leq 250$ & $233(66.8)$ \\
\hline $251-500$ & $53(15.2)$ \\
\hline $501-1000$ & $51(14.6)$ \\
\hline$\geq 1001$ & $12(3.4)$ \\
\hline
\end{tabular}

${ }^{*}$ Reason for testing and income was not recorded for 19 patients, $\mathrm{N}=$ number, $\mathrm{ART}$ = Anti-retroviral therapy 


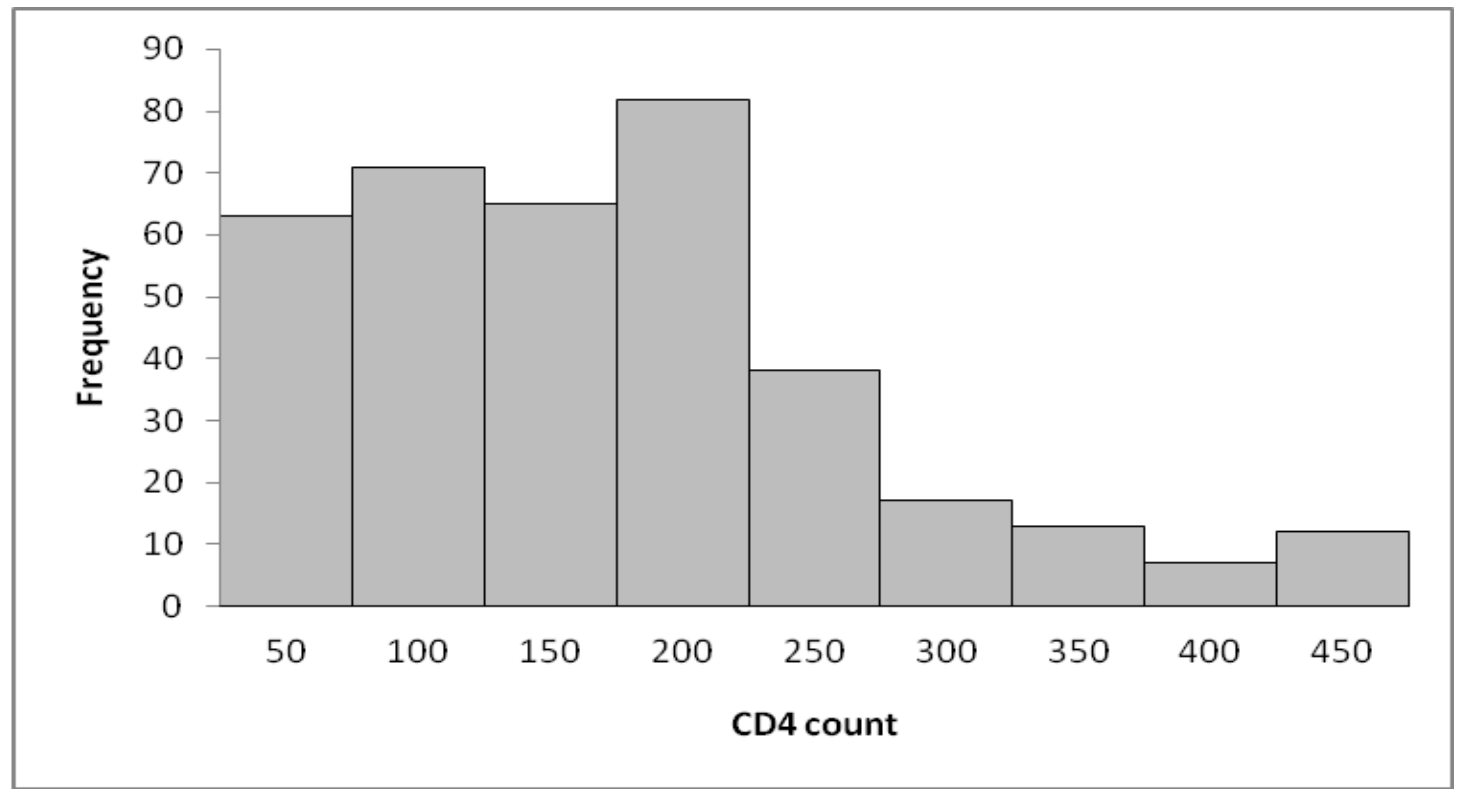

Figure 1: The distribution of CD4 cell count among untreated HIV-positive patients at initiation of ART at Felege Hiwot Hospital, Ethiopia, 2008.

Table 2: Number of ART naïve HIV patients diagnosed with common opportunistic infections by sex at Felege Hiwot Hospital, Ethiopia, 2008

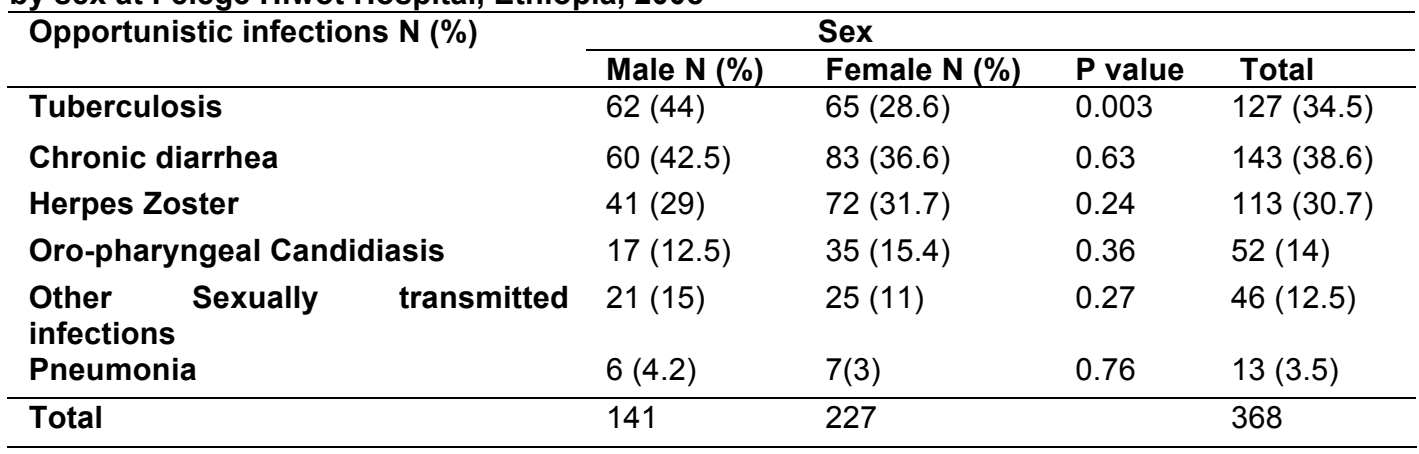

\section{CD4 cell counts}

At baseline, the mean CD4 cell count for both sexes was 153 cells/ $\mu 1$ (95\% CI: 139-167). The mean CD4 cell count was 156 cells $/ \mu 1$ (95\% CI: 137-175) for females and 122 cells $/ \mu 1$ (95\% CI: 105-139) for males $(\mathrm{P}=0.002)$. Two hundred and eighty $(76.3 \%)$ of the HIV- infected patients had CD4 cell count of less than 200 cells/ $\mu 1$ and therefore had AIDS and $134(36.4 \%)$ had CD4 cell counts $\leq 100$ cells/ $\mu 1$. The overall mean CD4/ CD8 T cell ratio was 0.22 . One hundred twelve $(30.4 \%)$ patients had CD4/CD8 cell ratio between 0.01-0.09.

\section{Patient follow-up}

Follow-up CD4 cell counts were enumerated for only $225(61 \%)$ HIV positive patients as $143(38.8 \%)$ patients were lost to follow-up at 6 months of treatment. The mean CD4 cell count for these 225 follow-up patients increased from 143 at baseline to 261 cells $/ \mu 1$ (95\% CI: 240-282) at 6 month of treatment as shown in (Table 5). The mean number of CD4 cell gained was 117 cells/ $\mu 1$ in $81.8 \%$ (78\% from patients who had low baseline CD4 cells count or $<200$ cells $/ \mu 1)$ follow-up cases. Seventy two $(32 \%)$ HIV positive patients failed to attain CD4 cell count above 200 cells/ $\mu 1$ after 6 -month of treatment. Of these, $61(84 \%)$ were from those with low baseline CD4 cell count $(<200$ cells/ $\mu 1)$. Forty one $(18.2 \%)$ patients had a lower CD4 cell count after six month of treatment compared to the baseline count. Among 166 follow-up HIV patients who had CD4 count of $<200$ cells $/ \mu 1$ at baseline, 130 (78\%) showed an increment in CD4 cells count whereas, among 59 follow-up patients who had CD4 cell count of $>200$ cells/ $\mu$ l at baseline, $51(86 \%)$ had increased CD4 cells count although the difference was not statistically significant $(\mathrm{P}=0.15)$. 
Table 3: CD4 cell count among ART naïve HIV patients by age at Felege Hiwot Hospital,

\begin{tabular}{|c|c|c|c|c|c|c|c|}
\hline \multirow{2}{*}{$\begin{array}{l}\text { CD4 count cells/ul } \\
\text { At baseline }\end{array}$} & \multicolumn{7}{|c|}{ Age groups (year) } \\
\hline & $<20$ & $20-29$ & $30-39$ & $40-49$ & $50-59$ & $\geq 60$ & Total \\
\hline$<50$ & 3 & 16 & 27 & 15 & 2 & - & 63 \\
\hline $50-99$ & 1 & 24 & 28 & 10 & 8 & - & 71 \\
\hline $100-149$ & 1 & 26 & 27 & 9 & 2 & - & 65 \\
\hline $150-199$ & 3 & 30 & 26 & 14 & 7 & 2 & 82 \\
\hline $200-249$ & - & 11 & 13 & 10 & 4 & - & 38 \\
\hline $250-299$ & 1 & 6 & 9 & - & 1 & - & 17 \\
\hline $300-349$ & - & 7 & 5 & 1 & - & - & 13 \\
\hline $350-399$ & - & 3 & 4 & - & - & - & 7 \\
\hline$\geq 400$ & 2 & 5 & 4 & 1 & - & - & 12 \\
\hline Total & 11 & 128 & 143 & 60 & 24 & 2 & 368 \\
\hline
\end{tabular}

Table 4: Mean baseline CD4 cell count of ART-naïve HIV positive patients by gender at Feleg Hiwot Hospital, Ethiopia, 2008

\begin{tabular}{|c|c|c|c|}
\hline \multicolumn{4}{|c|}{ Mean CD4/CD8 cells } \\
\hline Sex & CD4 cells/ $\mu \mathrm{l}$ & CD8 cells/ul & CD4/CD8 ratio \\
\hline Female $(\mathrm{N}=227)$ & 156 & 809 & 0.23 \\
\hline Male $(N=141)$ & 122 & 829 & 0.2 \\
\hline$P$ value & 0.002 & $>0.05$ & \\
\hline Average & 153 & 833 & 0.22 \\
\hline
\end{tabular}

Table 5: CD4 cell counts at baseline and after six month ART of HIV patients at Felege Hiwot referral hospital, Ethiopia, 2008

\begin{tabular}{llll}
\hline CD4 cell/pl & $\begin{array}{l}\text { At baseline } \mathbf{( N = 3 6 8 )} \\
\mathbf{N ~ ( \% )}\end{array}$ & $\begin{array}{l}\text { At six month follow- up } \\
(\mathbf{N}=\mathbf{2 2 5})^{*} \mathbf{N}(\%)\end{array}$ & P value \\
\hline$<100$ & $134(36.4)$ & $18(8)$ & $<0.001$ \\
$100-200$ & $147(39.9)$ & $54(24)$ & $<0.001$ \\
$201-300$ & $55(14.9)$ & $60(26.6)$ & $<0.001$ \\
$301-400$ & $20(5.4)$ & $37(16.4)$ & $<0.001$ \\
$\geq 400$ & $12(3.3)$ & $56(25)$ & $<0.001$ \\
Mean CD4 cells (95\% Cl) & $153(139-167)$ & $261(240-282)$ & $<0.05$ \\
\hline *143 patients were lost to follow up & &
\end{tabular}

\section{Discussion}

In this study, the majority of ART-naïve HIV patients were females. A similar finding was reported by Braitsein et al; (11) from South Africa who stated that ART-naïve patients in low-income countries were more likely to be females. This is because females are biologically and socially more vulnerable to HIV infection in the developing countries (13). Most of the HIV infected patients enrolled in our study were young age between 20 and 40 years old who were sexually more active and thus have a higher risk of infection compared to the other age groups (13). Higher proportions of ARTnaïve HIV infected patients had low educational level and were from minimum income groups. These findings conform previous reports from the same study area (14) and elsewhere in Ethiopia which reported that HIV prevalence decreases significantly with increasing level of education (15).

At baseline, the mean CD4 cell count of ART-naïve HIV infected patients was lower $(153$ cells $/ \mu 1)$ than the reports from other countries (16). This could be due to delayed presentation and/or testing, differences in educational and socio-economic levels. Moreover, Tsegaye et al; (17) reported that healthy HIV-negative Ethiopians had lower mean CD4 cell counts $(775 / \mu 1)$ than other Africans and individuals from Western countries.

In our study, female HIV patients had higher mean CD4 cell counts than male $(\mathrm{p}<0.002)$ before ART was initiated. This is consistent with Kumarasamy et al; (18) report from India. This difference could be due to several 
reasons; HIV associated TB could be the contributing factor for the low CD4 count in males as the proportion of patients having TB was significantly higher in male HIV positive patients than females $(p=0.003)$. In addition, it may be due to a sex-related difference in the overall CD4 counts among males and females as reported by Tsegay et al; (17). HIV sero-negative Ethiopian females had relatively higher CD4 cell counts than HIV seronegative males.

Our data indicates that the majority of HIV patients started antiretroviral treatment with more advanced immunodeficiency status. Since the majority (76.3\%) of HIV patients had AIDS as defined by their CD4 cell counts $<200$ cells $/ \mu 1$, as shown in indicating advanced immune suppression at initiation of ART. This was significantly higher when compared to the studies conducted in Nigeria, south eastern United States and Thailand which reported a lower rate of AIDS at the initiation of ART (19-21).

Therefore, in the study hospital, delayed enrollment in ART program could be attributed by several factors. Moreover, Kiflie et al; (22) in the same hospital reported that more than $28.8 \%$ of HIV infected patients who were eligible to be on ART but never started ART, might be related to poor quality of HIV testing services in the existing delivery sites. The other possible factor may be due to fear of stigma. In Ethiopia, only one third of HIV infected persons disclosed their HIV status to their partner (23) further compromising the utilization of the counseling and testing and ART services. Moreover, it was noted that most (75.4\%) of HIV infected patients seeking medical care when they had debilitating conditions and recurrent illnesses and the majority of them have started ART within 6 months of diagnosis. A similar observation was made among South Africans where patients stared ART program with advanced immunodeficiency status (24). These findings indicate urgent need to promote early and enhanced HIV testing to enable HIV/AIDS patients to benefit from the expanding ART services.

The limitation of this study was a higher dropout rate as $143(38.8 \%)$ patients were lost to follow-up at 6 months of treatment. However, in the same hospital, about 36\% patients were failed to follow-up because of multiple factors which were documented (25). Phone calls were used to contact patients but we were unable to actively trace lost to follow-up cases. Some of the reasons for the failure to follow-up were serious illness and deteriorating health situation, change in address, undocumented transfer out to other hospitals, lack of support, financial reasons or death. Several studies reported that the proportion of patients on ART lost to follow-up varied in different settings ranging from $19 \%$ to $44 \%(11,19)$. Our data indicated that loss to follow-up would be an important issue in ART program in resource limited countries and shouldn't be overlooked during the initiation and expansion of the ART program. Tracing patients using only phone calls may not be feasible option in such areas where the majority of patients frequently change their addresses due to several reasons including stigma, socio-economic stress and luck of support.

The mean CD4 cell count for 225 follow-up cases increased from 143 to 261 cells/ $\mu 1$ (95\% CI: 240-282) after 6 month of treatment. This was comparable with report of Gautam et al; (26) in India. However, among treatment-naïve HIV patients, $72(32 \%)$ failed to attain CD4 cell count above 200 cells/ $\mu 1$ at 6 months. Lower CD4 cell counts $(<200$ cell $/ \mu 1)$ before staring ART had significantly associated with failure to attain CD4 cell count recovery as the majority of the 61 (84\%) of patients whose CD 4 cell count remained $<200$ cells $/ \mu 1$ at 6 month were from those group with low baseline CD4 cell count. A higher proportion of patients with baseline CD4 count $>200$ cells $/ \mu 1$ had increased CD4 cells count after 6 months of treatment than those with a lower baseline CD4 counts. Actually the difference was not significant. Lower baseline CD4 cell counts therefore may correlate with poor immune responses and thus determine the degree of morbidity and mortality related to HIV/AIDS as reported by other studies too (27-28).

In conclusion, in our setting, although good CD4 cells recovery in response to ART was documented in more than $81 \%$ of follow-up cases, HIV-positive patients were enrolled in ART program at decreased CD4 cells levels. Therefore, interventions need to be designed to promote early HIV testing and early enrollment of HIV infected individuals into ART services. As socio-demographic factors and lack of awareness about ART services, fear of stigma and discrimination compromise the utilization of ART program, improving public awareness by advocacy and social mobilization should be included in the ART service.

\section{Acknowledgements}

We acknowledge the Ethiopian Ministry of Science and Technology for funding this study. We greatly appreciate Bahir Dar Regional Health Research Laboratory for providing materials and reagents for this study. We are also grateful to the individuals who participated in this study.

\section{References}

1. UNAIDS/WHO. AIDS epidemic update. Geneva: WHO; 2009:Available from: URL: www.who.int

2. World Health Organization (WHO). Towards universal accessing. Scaling up priority HIV/AIDS intervention in the health sector. Progress report. Geneva: WHO; 2008.

3. Federal Ministry of Health (FMOH). Annual HIV/AIDS monitoring and evaluation report in Ethiopia. Addis Ababa, Ethiopia; 2006.

Ethiop J Health Dev. 2010;24(1) 
4. Federal Ministry of Health (FMOH). Guidelines for implementation of HIV/AIDS case management in Ethiopia: HAPCO; 2009.

5. Federal Ministry of Health (FMOH). Technical document for sixth report of AIDS in Ethiopia. Ethiopia: HAPCO; 2007.

6. Chan KC, Wong $\mathrm{KH}$, Lee SS. Universal decline in mortality in patients with advanced HIV-1 disease in various demographic subpopulations after the introduction of HAART in Hong Kong, from 1993 to 2002. HIV Med 2006; 7(3):186-92

7. Hogg RS, Yip B, Kully C, Craib KJ, O'Shaughnessy MV, Schechter MT, et al. Improved survival among $\mathrm{HIV}$-infected patients after initiation of triple-drug antiretroviral regimens. CMAJ 1999;160(5):659-65.

8. Sterne JA, Hernan MA, Ledergerber B, Tilling K, Weber R, Sendi P, et al. Long-term effectiveness of potent antiretroviral therapy in preventing AIDS and death: a prospective cohort study. Lancet 2005; 366(9483):378-84.

9. Dabis F, Balestre E, Braitstein P, Miotti P, Brinkhof WG, Schneider M, et al. Cohort Profile: Antiretroviral Therapy in Lower Income Countries (ART-LINC): international collaboration of treatment cohorts. Int J Epidemiol 2005; 34(5):97986.

10. Braitstein P, Brinkhof MW, Dabis F, Schechter M, Boulle A, Miotti P, et al. Mortality of HIV-1 infected patients in the first year of antiretroviral therapy: comparison between low-income and high- income countries. Lancet 2006; 367(9513):817-24.

11. World Health Organization (WHO). TB/HIV a Clincal Manual. $2^{\text {nd }}$ ed. Geneva: WHO, 2004.

12. Lawn SD, Wood R. How can earlier entry of patients into antiretroviral programs in low-income countries be promoted? Clin Infect Dis 2006; 42(3):431-2; author reply 2-3.

13. UNAIDS. HIV Epidemic a global update. United Nations World AIDS day report. Health Millions. 1998.

14. Alemu H, Mariam DH, Belay KA, Davey G. Factors predisposing out-of-school youths to HIV/AIDSrelated risky sexual behaviour in northwest Ethiopia. J Health Popul Nutr 2007; 25(3):344-50.

15. Bradley H, Bedada A, Brahmbhatt H, Kidanu A, Gillespie D, Tsui A. Educational attainment and HIV status among Ethiopian voluntary counseling and testing clients. AIDS Behav 2007; 11(5):736-42.

16. Saul J, Erwin J, Bruce JC, Peters B. Ethnic and demographic variations in HIV/AIDS presentation at two London referral centers 1995-9. Sex Transm Infect 2000; 76(3):215.

17. Tsegaye A, Messele T, Tilahun T, Hailu E, Sahlu T, Doorly $\mathrm{R}$, et al. Immunohematological reference ranges for adult Ethiopians. Clin Diagn Lab Immunol 1999; 6(3):410-4.
18. Kumarasamy N, Venkatesh KK, Cecelia AJ, Devaleenol B, Saghayam S, Yepthomi T, et al. Gender-based differences in treatment and outcome among HIV patients in South India. J Women Health (Larchmt) 2008; 17(9):1471-5.

19. Chasombat S, McConnell MS, Siangphoe U, Yuktanont P, Jirawattanapisal T, Fox K, et al. National expansion of antiretroviral treatment in Thailand, 2000-2007: program scale-up and patient outcomes. J Acquir Immune Defic Syndr 2009; 50(5):506-12.

20. Gay CL, Napravnik S, Eron JJ, Jr. Advanced immunosuppression at entry to HIV care in the Southeastern United States and associated risk factors. AIDS 2006; 20(5):775-8.

21. Nwokedi EE, Ochicha O, Mohammed AZ, Saddiq NM. Baseline CD4 lymphocyte count among HIV patients in Kano, Northern Nigeria. Afr J Health Sci, 2007; 14:4.

22. Kiflie YA, Yoseph OB, Tegegne AM. Evaluation of HIV/AIDS clinical care quality: the case of a referral hospital in North West Ethiopia. Int J Qual Health Care 2009; 21(5): 356-362.

23. Degefa A, Sanders EJ, Mekonnen Y, Messele T, Wolday D, Dorigo-Zetsma W, et al. Knowledge and attitudes towards antiretroviral therapy among factory workers participating in a cohort on HIV and AIDS, Addis Ababa, Ethiopia. Ethiop Med J 2003;41 Suppl 1:75-87.

24. Burns FM, Fakoya AO, Copas AJ, French PD. Africans in London continue to present with advanced HIV disease in the era of highly active antiretroviral therapy. AIDS 2001;15(18):2453-5.

25. FHAPCO. Monthly ART update as of September 10, 2007. 2007.

26. Gautam H, Bhalla P, Saini S, Dewan R. Correlation between baseline CD4 + T-Lymphocyte count and plasma viral load in AIDS patients and their early clinical and immunological response to HAART: a preliminary study. Indian J Med Microbiol 2008; 26(3):256-8.

27. Falster K, Petoumenos K, Chuah J, Mijch A, Mulhall B, Kelly M, et al. Poor baseline immune function predicts an incomplete immune response to combination antiretroviral treatment despite sustained viral suppression. J Acquir Immune Defic Syndr 2009; 50(3):307-13.

28. Lawn SD, Myer L, Bekker LG, Wood R. CD4 cell count recovery among $\mathrm{HIV}$-infected patients with very advanced immunodeficiency commencing antiretroviral treatment in sub-Saharan Africa. BMC Infect Dis 2006; 6:59. 